\title{
Molecular characterization and organs expression of cytochrome P450 1B1 from Japanese eel (Anguilla japonica)
}

\author{
Mohamed A. H. El-kady* ${ }^{* 1}$,Yoshio Kaminishi, and Takao Itakura \\ Laboratory of Marine Biotechnology, Faculty of Fisheries, Kagoshima University, 4- \\ 50-20 Shimoarata, Kagoshima 890-0056, Japan \\ ${ }^{1}$ National Institute of Oceanography and Fisheries, Alexandria, Egypt \\ *Email: mohamedalkady66@gmail.com
}

\section{ABSTRACT}

The CYP1 family, one of the gene families of the CYP superfamily, has four subfamilies deposited in the GenBank/EMBL so far; CYP1A, CYP1B, CYP1C, and the newly identified CYP1D. The metabolic activation and elimination of polyaromatic hydrocarbons, polychlorinated biphenyls, and aryl amines from fish body is largely mediated by the CYP enzymes. A new cDNA of the CYP1B subfamily encoding CYP1B1 was isolated from Japanese eel liver after a single intraperitoneal injection of $\beta$-naphthoflavone (BNF). The full-length cDNA obtained was $2985 \mathrm{bp}$ and contained a $5^{\prime}$ noncoding region of $294 \mathrm{bp}$, an open reading frame of $1626 \mathrm{bp}$ coding for 541 amino acids and a stop codon and a 3' noncoding region of $1065 \mathrm{bp}$. The predicted molecular weight of the protein was approximately $61.27 \mathrm{kDa}$. The deduced amino acid sequence of Japanese eel CYP1B1 showed $62 \%$ similarity to three-spined stickleback CYP1B1 and zebrafish CYP1B1. It exhibited similarities of $66 \%$ with that of killifish, Indian medaka and our previously reported carp CYP1B1 and -1B2 while the higher similarities (67 and 69\%) of the deduced amino acids was observed with that of Nile tilapia CYP1B1 and rainbow trout respectively. The percent identities of Japanese eel CYP1B1 cDNA showed similarities with those of the reported CYP1Bs of mammals of 57,57 , and $56 \%$ for human, rat, and mouse CYP1B1, respectively. Japanese eel CYP1B1 was aligned with the CYP1 sequences and has been deposited in the GenBank/EMBL data bank with the accession number AY518340. The phylogenetic tree constructed using the previously reported CYP1B sequences of mammals and fish suggested the closer relationship of the newly identified Japanese eel CYP1B1 to rainbow trout CYP1B1. QRT-PCR analysis of liver, kidney, gills and intestine revealed a distinct induced expression in liver, kidney and gills $(71.93,3.87$ and 539.56 respectively) while the constitutive expression (0.062) was observed in intestine.

Keywords: Anguilla japonica, $\beta$-naphthoflavone, cytochrome P450, CYP1B1.

\section{INTRODUCTION}

In aquatic animals that inhabit environments often contaminated with high levels of organic pollutants, the induction of CYP genes as well as the catalytic activity of their products can serve as a sensitive biomarker for environmental contamination by dioxin and other chemical compounds (Payne 1976; Goksoyr 1995; Monostory et al., 1996). Cytochrome P450 enzymes are intermediates to the metabolic activation of polyaromatic hydrocarbons (PAHs), polychlorinated biphenyls (PCBs), and aryl amines. The cytochrome P450 enzymes catalyze the metabolic reactions of a variety of substrates from endogenous compounds such as steroids, fatty acids, vitamins, prostaglandins, and retinoids to numerous exogenous chemicals such as drugs, 
carcinogens, mutagens, and other chemical pollutants often resulting from combustion process (Nebert \& Gonzalez, 1987; Guengerich, 1990; Porter \& Coon, 1991; Coon et al., 1996; Nelson et al., 1996). Compared with humans that possess three CYP1 genes named CYP1A1, CYP1A2 and CYP1B1 (Nebert \& Russell, 2002), fish such as medaka, zebrafish and killifish possess five genes: CYP1A, CYP1B1, CYP1C1, CYP1C2 and CYP1D1 (Goldstone et al., 2007, 2009). Until the recent identification and characterization of the CYP1B1 gene in mammals (Savas et al., 1994, Bhattacharyya et al., 1995, Walker et al., 1995, Tang et al., 1996) and fish (Leaver \& George, 2000, Godard et al., 2000, El-Kady et al., 2004a,b, Willett et al., 2006, HouChu et al., 2008, Zanette et al., 2009; 2010), CYP1A1 and CYP1A2 were the main CYP1 family members held responsible for the oxidation and activation of PAHs, PCBs and aryl amines. Some laboratory chemicals like $\beta$-naphthoflavone (BNF) and 3-methylcholanthrene (3-MC) are regarded as prototypical PAHs-type inducers of $C Y P$ genes. These chemicals exert their effects on mammalian CYP1A and CYP1B through the interaction of the ligand-bound aromatic hydrocarbon receptor (AHR) and its specific binding sequences located upstream of the respective target genes (Hakinson, 1995; Zhang et al., 1998; Buters et al., 1999). The isolated five CYP1s from fish present a markedly distinct organ-specific distribution in the gene expression levels suggesting that different physiological roles could exist (Jönsson et al., 2007b; Goldstone et al., 2009). Up to date, only a single isoform of CYP1B has been identified from all fish species, whereas both CYP1B1 and CYP1B2 genes have been cloned in carp (Cyprinus carpio).

Recent studies on metabolism and carcinogenesis have shown mammalian CYP1B1 to be a critical and in some cases, necessary enzyme in the activation of several pollutants, notably the PAH 7,12-dimethylbenzene[a]anthrathene (DMBA) (Buters et al., 1999; Chun and Kim, 2003). They reported that CYP1B1 is located exclusively at extrahepatic sites and mediates the carcinogenesis of DMBA. Also, Shimada et al., 1996; 2002) reported that CYP1B1 participates with CYP1A1 and CYP1A2 in the activation of 2,3,7,8-tetrachlorodibenzo-p-dioxin, benzo[a]pyrene and related carcinogens causing initiation of cancers in human and mice. CYP1B1 is also potentially playing a role in endocrine regulation and estrogen-induced carcinogenesis (Hayes et al., 1996). Human CYP1B1 has been shown to metabolize $17 \beta$-estradiol to a 4-hydroxylated product, a chemical considered to cause breast cancer in women (Spink et al., 1998).

In contrast to CYP1As which have been identified in most vertebrate groups (mammals, birds, fish), CYP1Bs have been identified in a few mammal and fish species. The Genbank survey on fish CYP1Bs revealed only nine sequences; our previously reported carp $C Y P 1 B 1$ and $-1 B 2$, Nile tilapia sequence from our laboratory, and CYP1B1 sequences of plaice, catfish, Indian medaka, killifish, rainbow trout and zebrafish.

In this study, a cDNA of the CYP1B1 gene was isolated from the liver of BNFtreated Japanese eel and sequenced. Phylogenetic analysis was also performed to assess the relationship of this newly identified CYP1B1 gene with the other CYP1B subfamily members. Also the expression pattern of CYP1B1 mRNA was determined in liver, kidney, intestine and gills using QRT- PCR. 


\section{MATERIALS AND METHODS}

\section{Fish treatment and RNA preparation}

Japanese eel (Anguilla japonica) with a mean weight of $400 \mathrm{~g}$ were obtained from a commercial source and were treated with a single intraperitoneal injection of BNF $(100 \mathrm{mg} / \mathrm{kg})$ suspended in corn oil. Similar control fish were intraperitoneally injected at the same time with an equivalent volume of the vehicle (corn oil). Three days under fasting conditions, the treated and the control fish were killed and samples of the liver, kidney, intestine and gills were collected, immediately frozen in liquid nitrogen, and stored at $-80{ }^{\circ} \mathrm{C}$. Total RNA was isolated from $2 \mathrm{~g}$ of each of the samples of frozen liver, kidney, intestine and gills according to the Standard Acid Guanidinium Thiocyante Phenol Choloroform (AGPC) extraction method (Chomczynski \& Sacchi, 1978). Total RNA concentration and purity were determined spectrophotometrically as described by Sambrook \& Russel (2001), and A260/A280 ratios were between 1.7 and 1.9. Poly (A)+ RNA was purified using an Oligotex-dt30 $<$ super $>$ mRNA purification kit (Takara, Japan).

\section{Reverse transcription for full-length cDNA generation}

Reverse transcription of mRNA was performed with Superscript II reverse transcriptase (Gibco BRL, USA) to generate 5'-RACE-Ready and 3'-RACE-Ready first-strand cDNAs using the SMART ${ }^{\mathrm{TM}}$ RACE (rapid amplification of cDNA ends) cDNA amplification kit (Clontech, USA). According to the manufacturer's protocol, 3'- and 5'-RACE Ready cDNA to be used as a template in the 3' and 5' RACE PCR respectively.

\section{3 ' and 5'-RACE PCRs for full-length cDNA}

We designed one sense (F) and an antisense (R) primer specific to Japanese eel CYP1B1 for 3' and 5' RACE PCRs, respectively. The primer sequences were designed from short sequence obtained at our laboratory and is given in Table 1. The sense and antisense gene specific primers were used in combination with the universal primer mix (UPM) of the RACE PCR kit to generate the RACE PCR products. The RACE PCR reactions with the reverse transcription (RT) products obtained were conducted according to the principles of touch down PCR in order to avoid spurious amplifications (Don et al., 1991).

Table 1: Oligonucleotide primers used in the PCR amplification of Japanese eel CYP1B1 cDNA fragments.

\begin{tabular}{|l|c|c|}
\hline Primer & \multicolumn{1}{|c|}{ Nucleotide sequence } & Nucleotide location \\
\hline F & 5' GTTTATCGATGCAACGCTCAGGC & 2111 to 2133 \\
\hline R & 5'-GCCGATCACAGGTCATGCTTAGTA & 597 to 574 \\
\hline UPM (long) & 5'-CTAATACGACTCACTATAGGGCAAGCAGTGGTATCAACGCAGAGT & \\
\hline UPM (short) & 5'-CTAATACGACTCACTATAGGGC & \\
\hline
\end{tabular}

The cycle conditions for RACE PCR were as follows: 5 cycles of denaturation for $5 \mathrm{~s}$ at $94^{\circ} \mathrm{C}$ and annealing for $3 \mathrm{~min}$ at $72{ }^{\circ} \mathrm{C}$; 5 cycles of $94{ }^{\circ} \mathrm{C}$ for $5 \mathrm{~s}, 70{ }^{\circ} \mathrm{C}$ for $10 \mathrm{~s}$, and $72{ }^{\circ} \mathrm{C}$ for $3 \mathrm{~min}$; and 35 cycles of $94{ }^{\circ} \mathrm{C}$ for $5 \mathrm{~s}, 68^{\circ} \mathrm{C}$ for $10 \mathrm{~s}$, and $72{ }^{\circ} \mathrm{C}$ for 3 min. The DNA band of expected size was excised with a scalpel, purified using a GFX PCR DNA and a gel band purification kit (Amersham Biosciences, USA). The PCR products were subjected to restriction mapping with various enzymes and were cloned into PT7BlueT-vector (Novagen, USA). Purified plasmids were directly sequenced by dye terminator cycle sequencing using the ABI PRISM dye terminator cycle sequencing kit (PE Biosystemes, USA) and an Applied Biosystems 3100 DNA Sequencer. 


\section{Phylogenetic analysis}

DNA sequences with the following GenBank accession numbers were retrieved from the database and used in the phylogenetic analysis: DQ088663 (channel catfish CYP1B1), FJ786959 (killifish CYP1B1), HQ202282 (three-spined stickleback fish CYP1B1), NM_001174149 (rainbow trout CYP1B1), JX4546651 (Indian medaka CYP1B1), AY727864 (zebrafish CYP1B1), AY437774 (carp CYP1B1), AY437775 (carp CYP1B2), HQ829968 (Nile tilapia CYP1B1), U03688 (human CYP1B1), U09540 (rat CYP1B1) and X78445 (mouse CYP1B1). In order to determine homology among CYP1B subfamily cDNAs or deduced amino acid sequences of various species, sequence alignments were performed by the CLUSTAL W multiple sequence alignment method (online alignment site constructed by Kyoto University, Japan, http://www.genome.jp/tools/clustalw/). The phylogenetic tree was constructed by unweighted pair group method (UPGM) using the amino acid sequences of the previously reported CYP1B subfamily sequences of teleosts and mammals.

\section{CYP1B1 expression in different organs of Japanese eel using QRT- PCR Reverse} transcription

Reverse transcription of the RNA samples isolated from liver, kidney, intestine and gills was performed using Primescript ${ }^{\mathrm{TM}} \mathrm{RT}$ reagent kit (Takara, Japan) according to the manufacturer's instructions. Reactions were incubated for $15 \mathrm{~min}$ at $37^{\circ} \mathrm{C}$ then $5 \mathrm{~s}$ at $85^{\circ} \mathrm{C}$ to inactivate the reverse transcriptase. RT products were stored at $4^{\circ} \mathrm{C}$ for further PCRs.

\section{Primer design for QRT- PCR reaction}

Primers for Japanese eel CYP1B1 cDNA were designed using Laser gene primer select program (Ver. 5.52, 2003, DNASTAR Inc), with melting temperatures $(\mathrm{Tm})$ ranging from 58 to $60^{\circ} \mathrm{C}$, and amplicon lengths of 50 to $150 \mathrm{bp}$. The primer sequences are given in Table (2).

Table 2: Oligonucleotide primers used in the QRT- PCR amplification of Japanese eel probe.

\begin{tabular}{|l|l|l|c|}
\hline Primer & \multicolumn{1}{|c|}{ Nucleotide sequence } & Nucleotide location & Product length \\
\hline F & 5'- GTTTATCGATGCAACGCTCAGGC & 2111 to 2133 & $92 \mathrm{bp}$ \\
\hline R & 5'- TGAGGACAACAACAACAACAACTA & 783 to 806 & \\
\hline
\end{tabular}

\section{Quantitative Real-time PCR conditions and analysis}

Each PCR reaction consisted of $10 \mu$ of $\mathrm{SYBR}^{\mathrm{R}}$ Premix Ex Taq ${ }^{\mathrm{TM}}$ II $(2 \mathrm{X}), 10$ $\mu \mathrm{M}$ of each primer, $2 \mu \mathrm{l}$ of cDNA template and double distilled water to a final volume of $20 \mu \mathrm{l}$. All standard plasmid DNA dilutions, template controls and induced samples were run in triplicates. Reactions were then analyzed on an ABI 7300 RealTime PCR system under the following conditions: 35 cycles of $94^{\circ} \mathrm{C}$ for $30 \mathrm{~s}, 58^{\circ} \mathrm{C}$ for $30 \mathrm{~s}$ and $72^{\circ} \mathrm{C}$ for $3 \mathrm{~min}$. The relative quantification relates the PCR signal of the target transcript in a treatment group to that of another sample such as an untreated control (calibrator). For quantification of induced Japanese eel CYP1B1 normalized to an untreated control, standard curves were prepared for both the induced and the untreated reference. Each of the normalized induced Japanese eel CYP1B1 values was divided by the untreated control normalized value to generate the relative expression levels. Accordingly, CYP1B1 mRNA levels were reported as fold change in abundance relative to the average calibrator response.

\section{Statistical analysis}

The statistical differences between the groups were determined, and the data expressed as mean \pm standard deviation. Excel (Microsoft, NY) were used to analyze the data, and Student's t test was used for the comparisons. A P-value $<0.05$ was considered significant. At least three determinations were carried out for each data point. 


\section{RESULTS}

\section{Nucleotide sequence analysis}

Figure, 1 shows the full-length cDNA sequence (2985 bp) of Japanese eel cytochrome P450, CYP1B1. The obtained nucleotide sequence of Japanese eel CYP1B1 contained a 5' noncoding region of $294 \mathrm{bp}$, an open reading frame (ORF) of 1626 bp coding for 541 amino acids and a stop codon, and a 3 ' noncoding region of $1065 \mathrm{bp}$. The predicted molecular weight of the protein was approximately 61.27 $\mathrm{kDa}$. The sequence has one polyadenylation signals (AATAAA) and a poly A tail of 30 nucleotides. This sequence was aligned with the CYP1 sequences and has been deposited in the GenBank/EMBL data bank with the accession number AY518340.

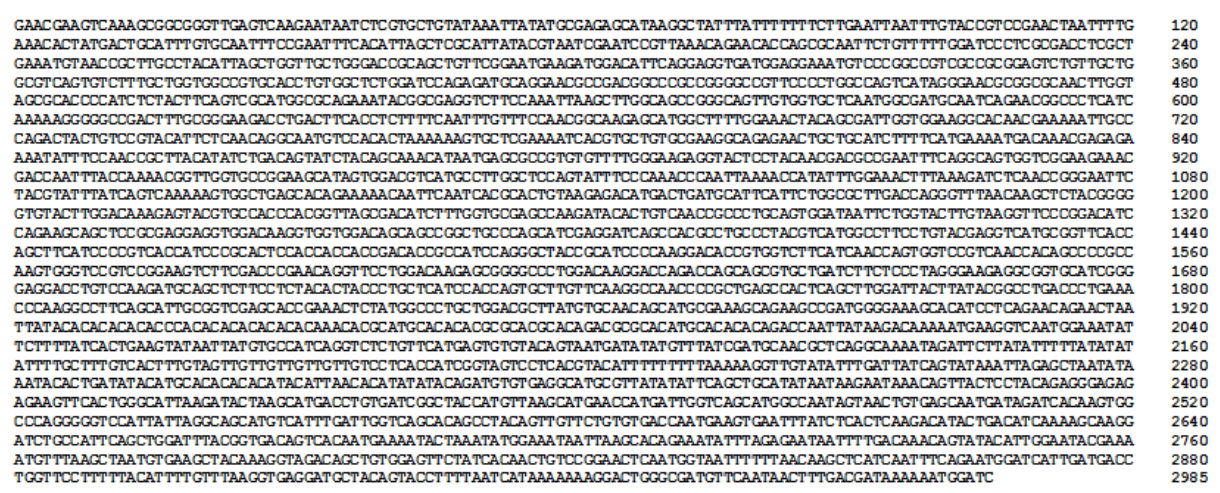

Fig. 1: Nucleotide sequence (2985 bp) of Japanese eel cytochrome P450 CYP1B1 cDNA. Consensus sequence for polyadenylation signal is bolded.

\section{Comparison of amino acid sequences}

The open reading frame and its deduced amino acid residues of Japanese eel cytochrome P450, CYP1B1 cDNA is shown in Figure 2. Table 3 shows the similarity percentage of the deduced amino acid sequences of Japanese eel CYP1B1 with those of the previously reported other CYP1B1 members. The deduced amino acid sequence of Japanese eel CYP1B1 showed $62 \%$ similarity to three-spined stickleback CYP1B1 and zebrafish CYP1B1. It exhibited similarities of $66 \%$ with that of killifish, Indian medaka and our previously reported carp CYP1B1 and $-1 B 2$ while the higher similarities (67 and 69\%) of the deduced amino acids was observed with that of Nile tilapia CYP1B1 and rainbow trout respectively. The percent identities of Japanese eel CYP1B1 cDNA showed similarities with those of the reported CYP1Bs of mammals of 57,57 , and $56 \%$ for human, rat, and mouse CYP1B1, respectively.
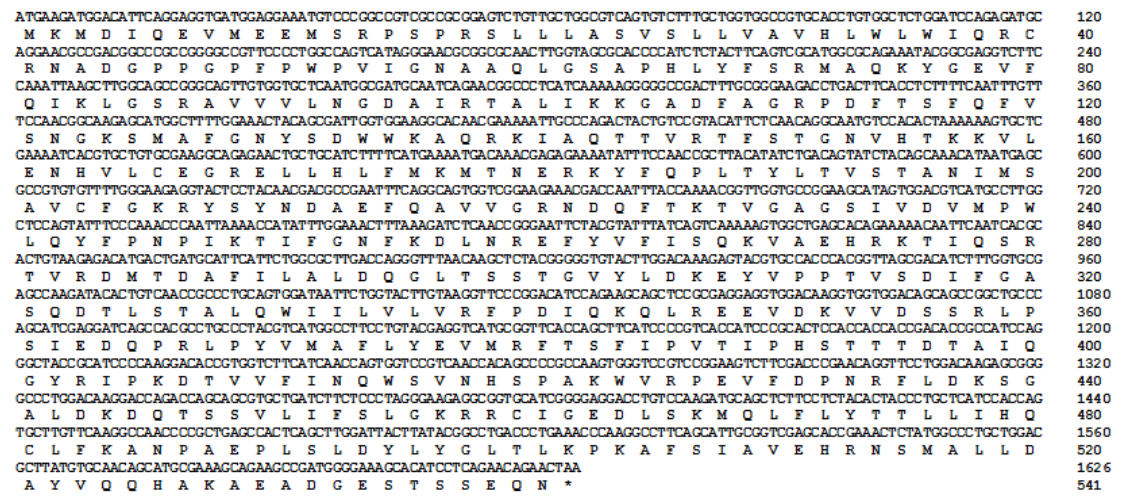

Fig. 2: The open reading frame (ORF) and its deduced amino acid residues of Japanese eel cytochrome P450 CYP1B1 cDNA. 
Table 3: Percent identities of deduced amino acid seauences of CYP1B subfamilv genes.

\begin{tabular}{|c|c|c|c|c|c|c|c|c|c|c|}
\hline & $\begin{array}{r}\text { carp } \\
1 \mathrm{B1}\end{array}$ & $\begin{array}{l}\text { carp } \\
1 \mathrm{~B} 2\end{array}$ & $\begin{array}{c}\text { Indian medaka } \\
\text { IB1 }\end{array}$ & $\begin{array}{l}\text { zebrafish } \\
\text { 1B1 }\end{array}$ & $\begin{array}{l}\text { three-spined } \\
\text { 1B1 }\end{array}$ & $\begin{array}{l}\text { rainbow trout Hile } \\
\text { 1B1 }\end{array}$ & $\begin{array}{l}\text { tilapia } \\
\text { IB1 }\end{array}$ & $\begin{array}{l}\text { killifish } \\
\text { IB1 }\end{array}$ & $\begin{array}{r}\text { human } \\
\text { 1B1 }\end{array}$ & $\begin{array}{c}\text { mouse } \\
\text { 1B1 }\end{array}$ \\
\hline Japanese eel 1B1 & 66 & 66 & 66 & 62 & 62 & 69 & 67 & 66 & 57 & 56 \\
\hline $\operatorname{carp} 1 \mathrm{~B} 1$ & & 91 & 63 & 84 & 61 & 63 & 60 & 61 & 55 & 54 \\
\hline carp 1B2 & & & 63 & 84 & 61 & 64 & 60 & 62 & 56 & 54 \\
\hline Indian medaka 1B1 & & & & 60 & 74 & 67 & 76 & 74 & 58 & 57 \\
\hline zebrafish 181 & & & & & 68 & 61 & 63 & 65 & 57 & 55 \\
\hline three-spined $1 \mathrm{~B} 1$ & & & & & & 68 & 78 & 76 & 60 & 58 \\
\hline rainbow trout $1 \mathrm{~B} 1$ & & & & & & & 70 & 65 & 54 & 53 \\
\hline Hile tilapia $1 \mathrm{~B} 1$ & & & & & & & & 73 & 56 & 56 \\
\hline killifish 181 & & & & & & & & & 59 & 59 \\
\hline human 1B1 & & & & & & & & & & 81 \\
\hline mouse $1 \mathrm{~B} 1$ & & & & & & & & & & \\
\hline
\end{tabular}

\section{Phylogenetic analysis}

The phylogenetic tree based on the amino acid sequences of CYP1Bs of teleost and mammalian species is shown in Figure, 3. The higher similarity (69\%) of the deduced amino acid sequences between Japanese eel CYP1B1 and that of rainbow CYP1B1 resulted in the clustering of the two genes in one branch apart from other CYP1Bs.

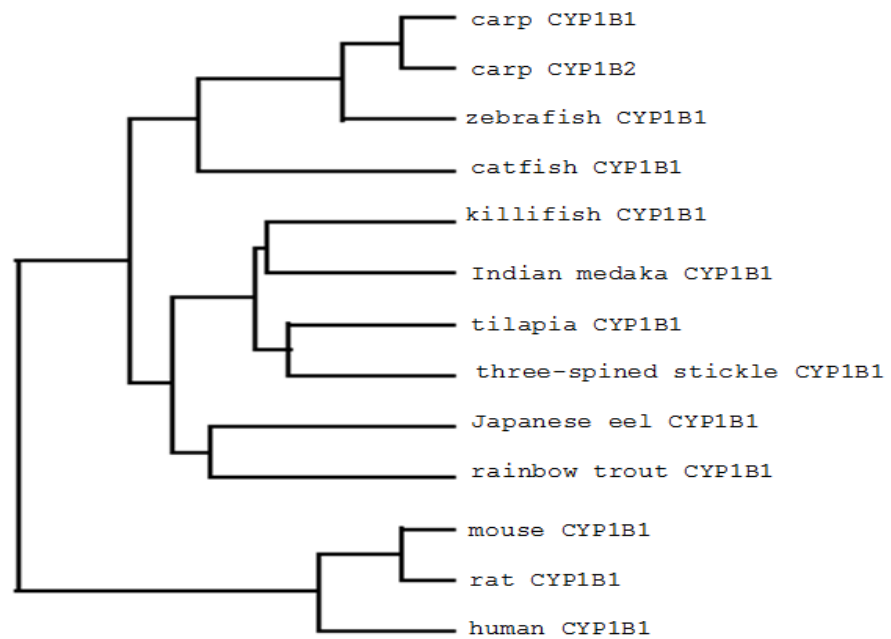

Fig. 3: Phylogenetic tree of ('YPIB subfamily genes constructed by pair group unweighted method (UPGM) using the amino acid sequences of teleosts and mammals.

\section{CYP1B1 mRNA level in different tissues of BNF treated Japanese eel}

QRT-RCR results revealed that there was a large increase in CYP1B1 mRNA in gills (539.56 fold), followed by liver (71.93), and kidney (3.78) while the constitutive expression was observed with the induced intestine (0.062) (Table, 4) (Figure 4).

Table 4: QRT-PCR results for Japanese eel CYP1B1 mRNA

\begin{tabular}{|l|c|c|c|c|c|}
\hline \multicolumn{1}{|c|}{ Sample } & Mean Qty & Std Dev & Fold & t-value & $\operatorname{Pr}$ \\
\hline L.cont & 0.1309 & 0.05 & & 8.29 & $<0.005$ \\
L.ind & 9.4163 & 1.94 & 71.93 & & $* * *$ \\
K.cont & 5.0478 & 0.45 & & 3.12 & $<0.05$ \\
K.ind & 19.0766 & 7.77 & 3.78 & & $*$ \\
G.cont & 0.0025 & 0.00 & & 8.42 & $<0.005$ \\
G.ind & 1.3489 & 0.28 & 539.56 & & $* * *$ \\
I.cont & 0.48 & 0.10 & & -7.45 & $<0.005$ \\
I.ind & 0.0296 & 0.01 & 0.06 & & $* * *$ \\
\hline
\end{tabular}

L.cont $=$ Liver control; L.ind $=$ liver induced; K.cont $=$ kidney control; K.ind = kidney induced; G.cont = gill control; G.ind = gill induced; I.cont = intestine control; I.ind = intestine induced. 


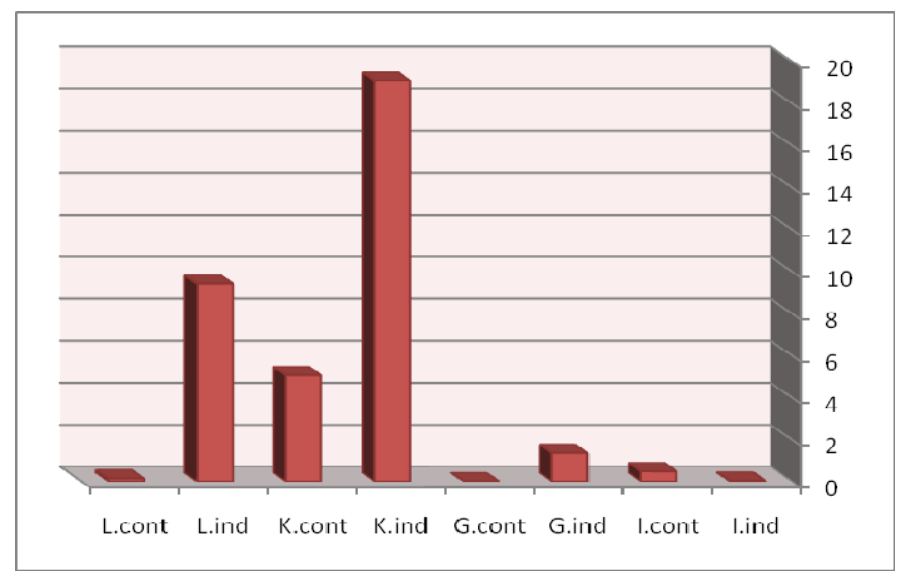

Fig. 4: The expression pattern of CYP1B1 in different organs of BNF-treated Japanese eel compared to the control; L. cont = Liver control; L. ind = liver induced; K. cont $=$ kidney control; $\mathrm{K}$. ind = kidney induced; G. cont = gill control; G. ind = gill induced; I. cont = intestine control; I. ind = intestine induced.

\section{DISCUSSION}

The obtained nucleotide sequence of Japanese eel CYP1B1 contained an open reading frame of $1626 \mathrm{bp}$ coding for 541 amino acids. Carp CYP1B1 and -1B2 ORF were found to code for 530 amino acids (El-Kady et al., 2004a, b) while the ORF of tilapia was found to code for only 531 amino acids (Hassanain et al., 2013). The ORF of the other CYP1B1 subfamily members coding for 514, 525, 526, 536, 537 and 541 for Indian medaka, three-spined stickleback fish, zebrafish, catfish, killifish and rainbow trout CYP1B1 respectively.

The phylogenetic tree based on the amino acid sequences of CYP1B of teleost and mammalian species showing the clustering of the newly identified Japanese eel CYP1B1 sequence with that of rainbow trout sequence in one branch showing a closer relationship to each other apart from other CYP1Bs.

In the present study, QRT-PCR results revealed that there was a large increase in CYP1B1 mRNA in gills (539.56 fold), followed by liver (71.93), and kidney (3.78) while the constitutive expression was observed with the induced intestine (0.062). Concerning CYP1B1 expression levels in other fish species, studies on plaice CYP1B1 expression reported more restricted tissue expression profile, only being detectable in gill tissue suggesting a role in gas and fluid regulation (Leaver \& George, 2000). Carp exposed to 3-MC had CYP1B1 messenger RNA expression in liver, intestine, and gill, while CYP1B2 was only induced in the gills (El-Kady et al., 2004a, b). Similarly, BaP-exposed catfish had significant CYP1B1 mRNA induction in blood, liver, and gonad tissues while the high constitutive expression was detected in gill (Willett et al., 2006). The Constitutive expression of CYP1B1 was restricted to gills of Trematomus bernacchii, an Antarctic fish where it was also induced by BNF (Di Bello et al., 2007). Dorrington et al., (2012) stated that the induction of Brazilian guppy with 3$\mathrm{MC}$ revealed the strong induced expression of CYP1B1 in the gill. Also the same result was observed with the expression of mRNA of three-spined stickleback fish (Gasterosteus aculeatus) that revealed the induction of CYP1B1 and CYP1C1 in gills at all concentrations of effluent from drug manufacturing while effects on these genes in liver and brain were weak or absent (Beijer et al., 2013). On the other hand, Hassanain et al., 2013 reported that after intracoelomic injection with $\mathrm{BaP}$, the 
expression of CYP1B1 in Nile tilapia revealed a large increase in CYP1B1 mRNA in liver (22.8), intestine (2.0) and muscles (1.3). In adult zebrafish, the eye, the brain and the heart are the organs with the highest basal expression of CYP1B1 (Jönsson et al., 2007b). There is also a high basal expression of CYP1B1 in zebrafish embryos, possibly related to the development of the eye, brain or heart (Jonsson et al., 2007a).

Studies on human CYP1B1 revealed its expression constitutively in extrahepatic organs, including fetal tissue samples and is highly inducible in various organs by 2,3,7,8-tetrachlorodibenzo-p-dioxin and related compounds in experimental animal models (Shimada et al., 1996). CYP1B1 is also expressed in the eye in mammals, and is essential for normal eye development (Choudhary et al., 2006).

\section{CONCLUSION}

This study provides the first description of the molecular characterization of Japanese eel CYP1B1 and the relationship of this newly identified sequence with that of the previously reported CYP1B subfamily members of fish and mammals. Also the higher induction of Japanese eel CYP1B1 mRNA in gills; the tissue in direct contact with the environment, followed by liver and kidney, may have important implication for the possible endogenous functions in these organs.

\section{RERERENCES}

Beijer K., Gao K., Jönsson M.E., Larsson D.G.J., Brunström B. and Brandt I. (2013). Effluent from drug manufacturing affects cytochrome P450 1 regulation and function in fish. Chemosphere, 90: 1149-1157.

Bhattacharyya K.K., Brake P.B., Eltom S.E., Otto S.A. and Jefcoate C.R. (1995): Identification of a rat adrenal cytochrome $\mathrm{P} 450$ active in polycyclic hydrocarbon metabolism as rat CYP1B1. J. Biol. Chem.; 270 (19): 11595-11602.

Buters J.T.M., Sakai S., Richter T., Pineau T., Alexander D.L., Savas Ü., Doehmer J., Ward J.M., Jefcoate C.R. and Gonzalez, F.J. (1999): Cytochrome P450 CYP1B1 determines susceptibility to 7, 12-dimethylbenzo[a] anthracene-induced lymphomas. Proc. Natl. Acad. Sci. USA; 96: 1977-1982.

Chomczynski P. and Sacchi N. (1978): Single-step method of RNA isolation by acid guanidinium thiocyanate-phenol-chloroform extraction. Anal. Bio. Chem.; 162: 156-159.

Choudhary D., Jansson I., Sarfarazi M. and Schenkman J.B. (2006): Physiological Significance and Expression of P450s in the Developing Eye. Drug Metabol. Rev.; 38:337-352.

Chun Y.J. and Kim S. (2003): Discovery of cytochrome P450 1B1 inhibitors as a new promising anticancer agents. Med Res Rev; 23(6): 657-668.

Coon M.J., Vaz A.N. and Bestervelt L.L. (1996): Peroxidative reactions of diversozymes. FASEB J; 10: 428-434.

Di Bello D., Vaccaro E., Long V., Regoli F., Nigro M., Benedetti M., Gervasi P.G., and Pretti C. (2007): Presence and inducibility by ß-naphthoflavone of CYP1A1, CYP1B1 and phase II enzymes in Trematomus bernacchii, an Antarctic fish. Aquat. Toxicol.; 84: 19-26.

Don R.H., Cox P.T., Wainwright B.J., Baker K. and Mattick J.S. (1991): "Touchdown" PCR to circumvent spurious priming during gene amplification. Nucleic Acids Res; 19: 4008.

Dorrington T., Zanette J., Zacchi F.L., Stegeman J.J., Bainy A.C. (2012): Basal and 3- 
methylcholanthrene-induced expression of cytochrome P450 1A, 1B and 1C genes in the Brazilian guppy, Poecilia vivipara. Aquat. Toxicol.; 15; 124125:106-113.

El-kady M.A.H., Mitsuo R., Kaminishi Y. and Itakura T. (2004a): cDNA cloning, sequence analysis and expression of 3-methylcholanthrene-inducible cytochrome P450 1B1 in carp (Cyprinus carpio). Environ. Sci.; 11(4): 231-240.

El-kady M.A.H., Mitsuo R., Kaminishi Y. and Itakura T. (2004b): Isolation of cDNA of novel cytochrome P450 1B gene, CYP1B2, from carp (Cyprinus carpio) and its induced expression in gills. Environ. Sci.; 11(6): 345-354.

Gao K., Brandt I., Goldstone J.V. and Jönsson M.E. (2011): Cytochrome P450 1A. $\underline{1 \mathrm{~B} \text {, and } 1 \mathrm{C} \text { mRNA induction patterns in three-spined stickleback exposed to a }}$ transient and a persistent inducer. Comp. Biochem. Physiol. C Toxicol. Pharmacol. ;154 (1): 42-55.

Godard C.A.J., Leaver M.J., Said M.R., Dickerson R.L., George S. and Stegeman J.J. (2000): Identification of cytochrome P450 1B-like sequences in two teleost fish species (scup, Stenotomus chrysops, and plaice, Pleuronectes platessa) and in a Cetacean (striped dolphin, Stenella coeruleoalba). Mar. Environ. Res; 50: 710.

Goksoyr A. (1995): Use of Cytochrome P450 1A (CYP1A) in fish as a biomarker of aquatic pollution. Arch. Toxicol. Suppl.; 17:80-95.

Goldstone J.V., Jönsson M., Woodin B.R., Jenny M.J., Nelson D.R. and Stegeman J.J. (2009): CYP1D, a new cytochrome P450 subfamily in vertebrates: Constitutive expression in zebrafish. Arch. Biochem. Biophys.; 482(1-2): 7-16.

Goldstone J.V., McArthur A.G., Goldstone H.M.H., Morrison A.M., Tarrant A.M., Kern S.E., Woodin B.R. and Stegeman J.J. (2007): Cytochrome P450 1 genes in early deuterostomes (tunicates and sea urchins) and vertebrates (chicken and frog): Origin and diversification of the CYP1 gene family. Mol. Biol. Evol.; 24(12):2619-2631.

Guengerich F.P. (1990): Characterization of human cytochrome P450 enzyme in carcinogen metabolism. Asian Pac. J. Pharmacol.; 5: 327-345.

Hankinson O. (1995): The aryl hydrocarbon receptor complex. Annu. Rev. Pharmacol. Toxocol.; 35: 307-340.

Hassanin A.A.I., Kaminishi Y., Osman M.M.M., El-Kady M.A.H. and Itakura T. (2013): Molecular characterization of cytochrome P450 1B1 and effect of benzo(a) pyrene on its expression in Nile tilapia (Oreochromis niloticus). Afr. J. Biotechnol.; 12(48): 6682-66908.

Hayes C.L., Spink D.C., Spink B.C., Cao J.Q., Walker N.J. and Sutter T.R. (1996): 17 $\beta$-estradiol hydroxylation catalyzed by human cytochrome P450 1B1. Proc. Natl. Acad. Sci.; USA; 93(18): 9776-9781.

Hou-Chu Y., Hua-Pin T., Hsin-Yu C., Chin-Yi K., Wen-Shyong T., Donald R.B. and Chin-Hwa H. (2008): Influence of TCDD on Zebrafish CYP1B1 Transcription during Development. Toxicol. Sci.; 103(1):158-168.

Jönsson M.E., Jenny M.J., Woodin B.R., Hahn M.E. and Stegeman J.J. (2007a). Role of AHR2 in the Expression of Novel Cytochrome P450 1 Family Genes, Cell Cycle Genes, and Morphological Defects in Developing Zebra Fish Exposed to 3,3',4,4',5-Pentachlorobiphenylor 2,3,7,8-Tetrachlorodibenzo-p-dioxin. Toxicol. Sci.; 100(1): 180-193.

Jönsson M.E., Orrego R., Woodin B.R., Goldstone J.V. and Stegeman J.J. (2007b): Basal and 3,3,4,4,5-pentachlorobiphenyl-induced expression of cytochrome P450 1A, 1B and 1C genes in zebrafish. Toxicol. Appl. Pharmacol.; 221: 29-41. 
Leaver M., George S.G. (2000). A cytochrome P4501B gene from a fish Pleuronectes platessa. Gene; 256:83-91.

Monostory K., Jemnitz K. and Vereczkey L. (1996): Xenobiotic metabolizing enzymes in fish: diversity, regulation and biomarkers for pollutant exposure. Acta. Physiol. Hung.; 84: 369-381.

Nebert D.W. and Gonzalez F.J. (1987): P450 genes: structure, evolution, and regulation. Ann. Rev. Biochem.; 56: 945-93.

Nebert D.W. and Russell D.W. (2002): Clinical importance of the cytochromes P450. Lancet, 360:1155-1162.

Nelson D.R., Koymans L., Kamataki T., Stegeman J.J., Feyereisen R., Waxman D.J., Waterman M.R., Gotoh O., Coon M.J., Estabrook, R.W., Gunsalus I.C. and Nebert D.W. (1996): P450 superfamily: update on new sequences, gene mapping accession numbers and nomenclature. Pharmacogenetics, 6: 1-42.

Payne, J.F. (1976): Field evaluation of benzopyrene hydroxylase induction as a monitor for marine petroleum pollution. Science, 191(4230): 945-946.

Porter T.D. and Coon M.J. (1991): Cytochrome P-450: multiplicity of isoforms, substrates, and catalytic and regulatory mechanisms. J. Biol. Chem.; 266(21): 13469-13472.

Sambrook J. and Russell D.V. (2001): Molecular Cloning: A Laboratory Manual, $3^{\text {rd }}$ ed., Cold Spring Harbor Laboratory, NY, 1: 7.13-7.17.

Savas U., Bhattacharyya K.K., Christou M., Alexander D.L. and Jefcoate C.R. (1994): Mouse cytochrome P-450EF, representative of a new $1 \mathrm{~B}$ subfamily of cytochrome P-450s. J. Biol. Chem.; 69 (21): 14905-14911.

Shimada T., Hayes C.L., Yamazaki H., Amin S., Hecht S.S., Guengerich F.P. and Sutter T.R. (1996): Activation of chemically diverse procarcinogens by human cytochrome P-450 1B1. Cancer Res.; 56(13): 2979-2984.

Shimada T., Inoue K., Suzuki Y., Kawai T., Azuma E., Nakajima T., Shindo M, Kurose K., Sugie A., Yamagishi Y., Fujii-Kuriyama Y. and Hashimoto M. (2002). Arylhydrocarbon receptor-dependent induction of liver and lung cytochromes $\mathrm{P} 4501 \mathrm{~A} 1,1 \mathrm{~A} 2$, and 1B1 by polycyclic aromatic hydrocarbons and polychlorinated biphenyls in genetically engineered $\mathrm{C} 57 \mathrm{BL} / 6 \mathrm{~J}$ mice. Carcinogenesis, 23(7):1199-1207.

Spink D.C., Spink B.C., Cao J.Q., De Pasquale J.A., Pentecost B.T., Fasco M.J., Li Y. and Sutter T.R. (1998): Differential expression of CYP1A1 and CYP1B1 in human breast epithelial cells and breast tumor cells. Carcinogenesis, 19(2): 291298.

Tang Y.M., Wo Y.P., Stewart J., Hawkins A.L., Gariffin C.A., Sutter T.R. and Greenlee W.F. (1996): Isolation and characterization of the human cytochrome P450 CYP1B1 gene. J. Biol. Chem.; 271(45): 28324-28330.

Walker N.J., Gastel J.A., Costal L.T., Clark G.C., Lucier G.W. and Sutter T.R. (1995): Rat CYP1B1: an adrenal cytochrome P450 that exhibits sex-dependent expression in livers and kidneys of TCDD-treated animals. Carcinogenesis; 16 (6): 1319-1327.

Willett K.L., Ganesan S., Patel M., Metzger C.M., Quiniou S., Waldbieser G., Scheffler B. (2006): In vivo and in vitro CYP1B mRNA expression in channel catfish. Mar. Environ. Res.; 62: S332-S336.

Zanette J., Jenny M.J., Goldstone J.V., Woodin B.R., Watka L.A., Bainy A.C. and Stegeman J.J. (2009): New cytochrome P450 1B1, 1C2 and 1D1 genes in the killifish Fundulus heteroclitus: Basal expression and response of five killifish CYP1s to the AHR agonist PCB126. Aquat. Toxicol.; 93:234-243. 
Zanette J., Parente T., Jönsson M., Nelson D.R. and Stegeman J.J. (2010): Identification and Developmental Expression of the Full Complement of Cytochrome P450 Genes in Zebrafish. BMC Evol. Biol.; 11:643.

Zhang L., Savas Ü., Alexander D.L. and Jefcoate C.R. (1998): Characterization of the mouse Cyp1B1 gene: identification of an enhancer region that directs aryl hydrocarbon receptor-mediated constitutive and induced expression. J. Biol. Chem.; 273(9): 5174-5183.

\section{ARABIC SUMMARY \\ التوصيف الجزيئي وقياس التعبير الجينى للسيتوكروم P450 1B1 فى أعضاء ثُبان السمك اليابانى (Anguilla japonica)}

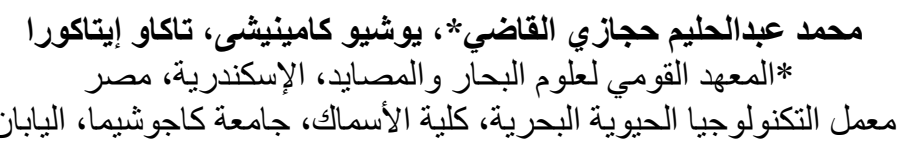

تعتبر عائلة السيتوكروم CYP1 ، إحدى العائلات الجينية للفصيلة CYBP /

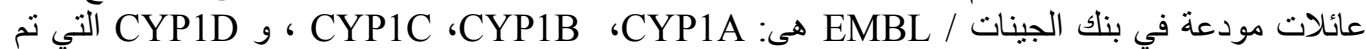

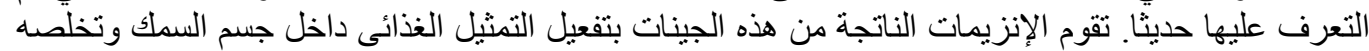

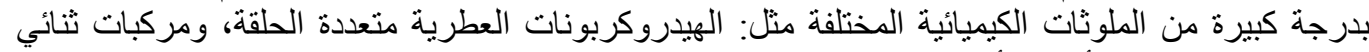
الفينيل متعدد الكلور ، وأريل الأمينات.

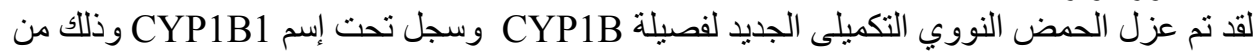

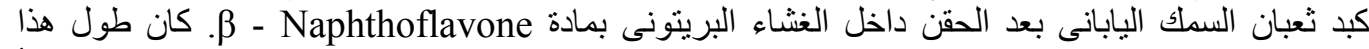

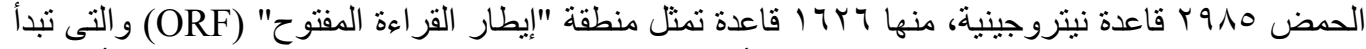

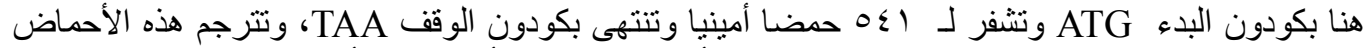

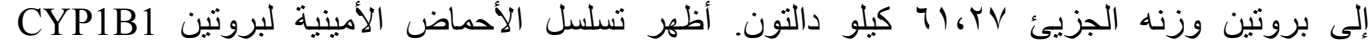

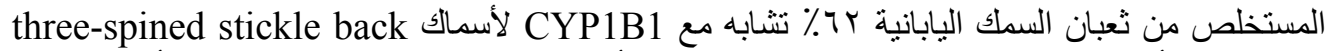

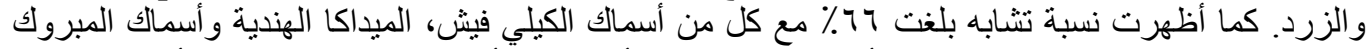

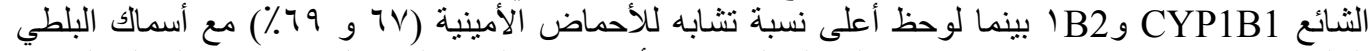

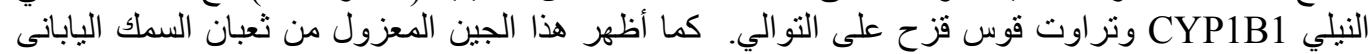

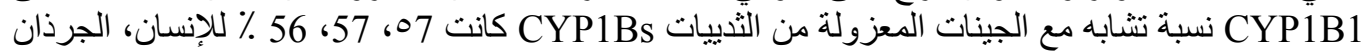

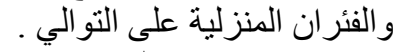

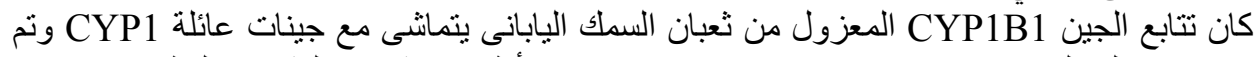
إيداعه في بيانات بنك الجينات EMBL تحت رقم

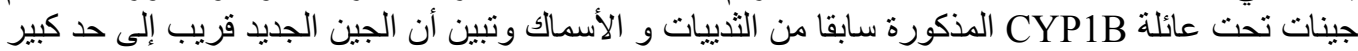

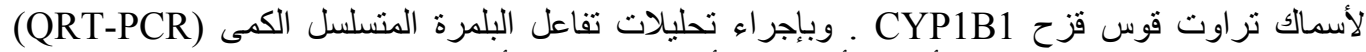

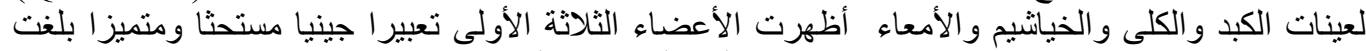

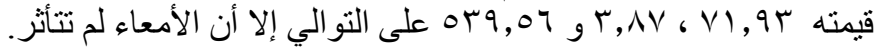

